\title{
Dos movimentos sociais às manifestações de rua: o ativismo brasileiro no século XXI
}

Ilse Scherer-Warren'

\section{Resumo}

Como distinguir os diferentes tipos de ativismo no Brasil atual a partir de suas formas de organização, formas de atuação pública, seus ideários, propostas ou reivindicações socioculturais e políticas? Tendo em vista este desafio, iniciaremos o artigo criando uma tipologia que nos permite distinguir movimentos sociais históricos de manifestações de rua conjunturais e verificar como e quando os movimentos sociais organizados se expressam politicamente através das manifestações públicas e em que medida as manifestações de rua excedem o espaço discursivo e politicamente estabelecido pelos movimentos sociais. A seguir será examinado se os movimentos sociais organizados vêm sendo impactados pelas manifestações de rua e incorporando ou consolidando demandas transversais em suas agendas políticas.

Palavras-chave: Movimentos sociais. Ativismo social. Manifestações de rua.

\section{Dos movimentos sociais às manifestações - uma tipologia}

Iniciaremos com a definição de um quadro analítico que nos permite distinguir diversas modalidades de organizaçóes do ativismo civil na sociedade contemporânea. Ainda que a realidade empírica tenda a ser mais complexa do que a teoria e com contradiçôes internas em suas formas de atuação, consideramos que a partir da construção de um quadro analítico para as diversas modalidades de ativismo teremos como diferenciar as formas de lutas cidadãs coletivas, referenciando-se especialmente na sociedade brasileira contemporânea a fim de compreender suas dinâmicas políticas internas e seu papel político na sociedade como um todo. Com este objetivo, construímos a seguinte tipologia:

Professora titular aposentada da Universidade Federal de Santa Catarina, professora voluntária e coordenadora do Núcleo de Pesquisa em Movimentos Sociais do Programa de Pós-Graduação em Sociologia Política da UFSC, Pesquisadora IA do CNPq e membro do INCT (Instituto Nacional de Ciência e Tecnologia) de Inclusão no Ensino Superior e na Pesquisa. Email: ilse@manezinho.com.br. 


\section{I - Movimentos sociais organizados:}

Características: organizados com algum arranjo institucional que vise sua continuidade temporal, principais objetivos políticos definidos ou em construção pelos militantes e um projeto ou utopia de mudança social, política ou cultural. Usam periodicamente o recurso das manifestaçôes públicas para reivindicaçóes e protestos específicos de suas lutas e para obter visibilidade política na esfera pública.

Exemplos: Movimento Passe Livre, Movimento dos Trabalhadores Sem Terra, Sem Teto e os vários movimentos sociais feministas, etnorraciais, estudantis e/ou da juventude, urbanos, ecológicos, sindicais etc.

\section{II - Manifestaçóes ou marchas dos movimentos sociais:}

Características: buscam visibilidade pública de suas pautas específicas através das marchas em espaços públicos, repetidas de forma ocasional ou regularmente. Referem-se a manifestaçóes históricas vinculadas aos movimentos sociais ou à sociedade civil organizados.

Exemplos: Marcha Zumbi dos Palmares, Grito dos Excluídos, Marcha das Margaridas, Marcha Mundial das Mulheres, Marcha da Maconha etc.

\section{III - Manifestaçóes amplas da cidadania elou dos "indignados":}

Características: agregados de múltiplos coletivos no espaço público com reivindicaçóes conjunturais, mas frequentemente com protestos politicamente heterogêneos, diversificados, e podendo conter antagonismos políticos explicitados ou não, e mobilizados especialmente através das redes sociais e/ou virtuais.

Exemplos: Diretas Já, Caras Pintadas, Manifestaçóes de Junho/2013 etc.

IV - Manifestaçôes-bloqueio ou "formas de ação nas ruas":

Características: têm uma tática ou estratégia de luta de pequenos grupos que frequentemente se apresentam de forma oportunista durante

2 Utilizo aqui denominação dada por Ned Ludd (2002, p. 9,15) a esse tipo de manifestação. Ned Ludd é um pseudônimo atribuido a um autor político coletivo que contribuiu com depoimentos que consta da coletânea "Urgência das ruas". 
manifestaçóes mais amplas, como as mencionadas anteriormente, e seguem princípios ideológicos principalmente do anarquismo de uma forma geral ${ }^{3}$.

Exemplos: Black Blocs, Anonymous etc.

\section{$\mathrm{V}$ - Ação-manifesto sociocultural:}

Características: apresenta expressão coletiva em espaços públicos para a afirmaçáo de direitos socioculturais para segmentos da populaçáo que se sentem excluídos, discriminados ou sem reconhecimento de suas singularidades.

Exemplos: Rolezinhos, Marcha das Vadias etc.

\section{Como distinguir movimentos sociais de manifestações?}

Os movimentos sociais organizados têm uma relativa permanência temporal e no mundo contemporâneo tendem a se estruturar sob a forma de redes de militância ${ }^{4}$ que operam como uma estratégia para a construção de significados políticos ou culturais em comum, tendo em vista conquistar e mobilizar cidadáos e produzir transformaçóes sociais.

Já as manifestaçōes de rua, em sentido estrito, são frequentemente reações conjunturais coletivas e públicas, que pretendem através do protesto criar visibilidade política, o reconhecimento das vozes dos cidadãos, seja através de seus movimentos ou do público em geral mobilizado para o evento político em si mesmo.

Assim sendo, o Movimento social organizado tende a possuir no mundo contemporâneo quatro momentos constitutivos relevantes, para sua permanência e continuidade como ator políticos:

1. Construir um "frame" ou engajamento organizacional (SCHERER-WARREN, 2012a), o qual inclui organizaçóes de base (grupos organizados,

3 Apesar de que em suas origens, na Alemanha, foi interpretado por alguns como um movimento com tendências fascistas ou de extrema direita (SCHLEMBACH, 20/3).

4 Para a conceituação de redes de movimentos sociais e de militância, e suas presenças na sociedade brasileira contemporânea, vide, especialmente, Scherer-Warren (20I2a; 20/4b).

5 Para outros desdobramentos e exemplos desses momentos constitutivos dos movimentos sociais, vide SchererWarren (20/2a; 20/2b). 
associaçōes, entidades civis, organizaçóes não governamentais - ONGs etc.), e entidades articuladoras e mediadoras, como fóruns, redes articuladoras ou semelhantes, onde se realiza a construção de significados comuns para as lutas na esfera pública.

2. Esses significados comuns são produzidos através de articulaçóes discursivas (LACLAU, 2011; MOUFFE, 2003; SCHERER-WARREN, 2013) para a construçáo de demandas, ideários e projetos comuns para uma mudança social, ainda que passíveis de constantes mutaçóes.

3. Demandas e ideários que serão traduzidos em açóes de advocacia por direitos, para a incidência nas politicas públicas ou para mudanças sociais, políticas, culturais elou sistêmicas'.

4. Enfim, o movimento organizado busca na manifestaçáo momento de protesto, reivindicação ou visibilidade, mas tem uma continuidade para além desse momento mobilizatório público (SCHERER-WARREN, 2014b). Os movimentos sociais promovem, participam ou estáo nas manifestaçóes, mas náo se reduzem a essas.

Por sua vez, a Manifestação de rua tende a se construir e se efetuar a partir de outros parâmetros:

Constrói-se como uma forma de evento político reativo a situaçóes ou fatos políticos indesejáveis ou para criar visibilidade a demandas coletivas nos campos socioeconômico, cultural ou político. Pode ser fruto de uma iniciativa dos movimentos sociais organizados ou da reação de cidadáos em geral ou, ainda, numa combinação de ambos. Esta última forma se torna cada vez mais comum na sociedade da informação, através das mobilizaçóes feitas por meio das redes sociais virtuais.

Quando o evento tem uma motivaçáo político-conjuntural recente (Diretas Já, Fora Collor, Copa do Mundo etc.), tende a se extinguir com a temporalidade do fato histórico.

As articulaçóes político-discursivas ${ }^{7}$ podem ocorrer especialmente se os eventos tiverem repetiçóes, mas são mais efêmeras e podem não ter

6 Vide outros desdobramentos e exemplos empíricos em Scherer-Warren (2011).

7 Sobre o uso da categoria "articulações discursivas", vide meu texto "Redes e movimentos sociais projetando o futuro", presente na obra de Scherer-Warren (20/3). 
continuidade se náo forem incorporadas principalmente por movimentos organizados que podem lhe dar continuidade e restabelecer ou recriar novos sentidos e ideários políticos, conforme veremos a seguir.

\section{Singularidades dos atores coletivos e seus discursos nas pós-manifestações de 2013}

Para entender e recuperar os discursos políticos dos principais atores coletivos nas manifestaçóes de rua de 2013, não podemos nos fixar apenas nas palavras de ordem e nos cartazes que circularam durante as manifestaçóes e na forma como foram utilizados pelas diversas mídias para interpretar os protestos. Devemos recuperar o antes e o depois do ato de se manifestar. As manifestaçóes expressaram o momento "multidáo" dos movimentos, que pode sugerir erroneamente um sentido de unidade, a qual pode ser uma unidade no ato de manifesto, ou de protesto, ou de direito a voz pública, mas náo necessariamente uma unidade na política ou na utopia para a transformaçáo. Para Hardt e Negri (2005), a “multidáo” distingue-se de povo, o qual constrói uma identidade na política, que em nossa história do século XX, por exemplo, foi denominada de "populismo" (LACLAU apud MARON, 2012), por apresentar uma lógica de formaçáo das identidades coletivas, as quais condensavam significados políticos em torno de demandas comuns. Por sua vez, a multidão, para Hardt e Negri (2005), expressa o encontro de "múltiplas identidades", que apesar das diferenças na política, cooperam tendo em vista o "benefício de uma relação comum". Isso ocorreu em certa medida nas manifestaçóes recentes no Brasil, porém com várias contradiçóes internas no conjunto de seus participantes em relação aos ideários, aos projetos e às utopias para a mudança. A cooperação nas manifestaçóes de 2013 focava-se principalmente na defesa do direito a dar voz pública às demandas plurais, mas assim mesmo o entendimento sobre a legitimidade das múltiplas demandas foi conflitivo entre vários subgrupos de manifestantes, e o engajamento partidário foi publicamente repudiado por alguns manifestantes. Portanto, as singularidades náo foram revertidas necessariamente no reconhecimento da diferença na política ou na cultura. Está sendo num processo de reflexáo política dos movimentos sociais específicos pós-manifestaçōes de 2013 que algumas novas identificaçóes na política estão sendo construídas entre diferentes grupos de manifestantes, conforme veremos mais adiante para o caso de coletivos de feministas e juvenis. 
Exemplificaremos a seguir os diversos tipos de açôes coletivas do ativismo contemporâneo na sociedade brasileira, utilizando o referencial anteriormente apresentado. Nessa direçáo, elegemos, na sequência, alguns dos movimentos e/ou manifestaçóes dos tipos anteriormente classificados, os quais consideramos emblemáticos ou paradigmáticos para pensar as mobilizaçóes mais recentes no país e para avaliar o impacto desses processos mobilizatórios nos discursos políticos dos atores coletivos e na e para as articulaçóes interorganizacionais movimentalistas.

\section{Movimentos sociais organizados}

\section{I Movimento Passe Livre (MPL) ${ }^{8}$}

Com base em pesquisas sobre o MPL (vide, especialmente, Saraiva (2010) e Cassoli (2010)), podemos resumir seu perfil e legados políticos como:

- Projeto principal do MPL: mudanças sistêmicas (direito à cidade para todos, socializaçáo da cidade); transformaçóes nos modos de vida e na participaçáo política (autonomia, apartidarismo, mas náo antipartidarismo, horizontalidade e açóes diretas etc.)

- Influências: novos movimentos sociais, neoanarquismo, neozapatismo e outras lutas alterglobalizaçáo e anticapitalismo "selvagem".

- Projeto inicial (para além do PL elou do preço da passagem): desmercantilizaçáo do transporte.

- Diálogos e Articulaçóes:

- Esquerda institucional: alguns partidos, sindicatos, ONGs, centrais sindicais, (Uniáo Nacional dos Estudantes - UNE, Diretórios Centrais dos estudantes - DCEs etc.;

- Na esquerda social: movimentos sociais (Movimento dos Trabalhadores Sem Terra - MST, Movimento dos Trabalhadores Desempregados - MTD, Movimentos dos Atingidos por Barragens - MAB, Ação Popular - AP etc.);

- Militantes/ativistas autônomos (concepçóes autonomistas, anarquistas, altermundistas etc.).

8 Elegemos o MPL por ter sido o desencadeador das manifestações de 2013 e por sua projeção na esfera pública. 
Como isso, expressou-se nas manifestaçóes de 2013: " $A$ revolta é contra o aumento das passagens, mas o movimento é outro [...]" (palavras de um militante).

A juventude que foi naquela quinta-feira (8/6/14) à noite ao Centro e à Paulista não está protestando só por conta de vinte ou trinta centavos a mais no preço da passagem. Isso é apenas um pedaço da história. A periferia brasileira está em movimento e em disputa. E se a cidade não passar a ser pensada para esses milhões de jovens, em breve algo muito maior do que aconteceu na quinta vai estourar.

O jovem pobre não quer só comida. E não quer só migalhas [...] Querem estar no Centro. Querem descatracalizar a cidade. Querem poder entrar e sair. Querem circular. O acesso ao transporte público ganha essa dimensão porque é parte direta desse problema. Mas ele não é nem o todo e nem tudo. Há muitas outras coisas em jogo. ${ }^{9}$

Portanto, para além das demandas materiais e políticas, estava no centro das manifestaçóes desses jovens também o desejo de mudanças nos modos de vida e na cultura. Nessa direção, a interpretaçáo de outro militante ${ }^{10}$ do MPL ajuda a ilustrar os vários momentos constitutivos do movimento, pós-manifestaçóes de junho/2013, em torno dos seguintes eixos de luta:

- Valorizaçáo da organizaçáo:

Acho que essa experiência da luta contra o aumento da tarifa trouxe um salto qualitativo muito importante. Essa tradição de luta que a gente remonta ao zapatismo, ao movimento antiglobalização, mais recentemente ao Occupy Wall Street, ao I5M, e lá atrás a maio de 1968, às lutas da autonomia italiana, essa tradição é muito marcada pela valorização do processo de organização.

- Valorizaçáo da performance através de articulaçóes discursivas transversais:

Ou seja, a ideia de que devemos fazer política pré-figurativa. Que a forma de organização do movimento deve espelhar a sociedade que a gente quer. Então ser horizontal, inclusivo, não ser sexista, não ser racista, um enorme cuidado com o processo. É processo político e

9 Relato de um manifestante. Disponivel em: <http://www.revistaforum.com.br/blogdorovai/20/3/06/08/arevolta-e-contra-o-aumento-das-passagens-mas-o-movimento-e-outro/>. Acesso em: mar. 2014.

10 Pablo Ortellado: experiência do MPL é "aprendizado para o movimento autônomo não só do Brasil como do mundo". Disponivel em: <http://coletivodar.org/2013/09/pablo-ortellado-experiencia-do-mpl-e-aprendizadopara-o-movimento-autonomo-nao-so-do-brasil-como-do-mundo/>. 
também criativo - então fazer intervenções divertidas, contraculturais, é a mesma valorização do processo: queremos uma vida prazerosa, desburocratizada das amarras institucionais $[\ldots]$

- A luta imediata e a luta de longo prazo:

E eu acho que a grande novidade aqui é que o MPL criou um novo paradigma. Ter um objetivo de curto prazo, que é um processo de uma utopia, de uma transformação mais profunda. Qual a transformação mais profunda? A desmercantilização do transporte. Direitos públicos à mobilidade urbana [...] E isso ampliou os horizontes [...] é um movimento autônomo, que faz essas discussões de que o processo tem que ser horizontal, independente dos partidos e etc., mas não descuida da conquista de objetivos práticos de curto prazo que vão acelerar essa passagem pro objetivo de longo prazo."

Trata-se, pois, de uma forma emergente de ser movimento, que articula as demandas "do aqui e agora" (preço da passagem) a um projeto ou utopia de transformaçáo mais amplo e duradouro, que inclui mudanças sistêmicas e relativas a um direito mais universal para a mobilidade urbana.

\subsection{Movimento Feminista"l}

Nós feministas, sempre protestamos. E quando vimos as multidões nas ruas, trazendo pautas que nos contemplavam, muitas de nós nos extasiamos com a possibilidade de que o poder da pressão e resistência popular traria mudança profunda na sociedade. Não estávamos mais sozinhas, éramos uma multidão [...] Que mundo é esse que essa multidão quer construir onde não há o mínimo respeito às diferenças" [...] E seguimos nós, protestando dentro dos protestos, dentro das nossas casas e das nossas músicas. Não temos balas de borracha [...] (GUERRA, 2013).

O Movimento Feminista se juntou às oportunidades que as manifestaçóes de 2013 traziam para dar visibilidade as suas lutas específicas, sem perder o rumo de seu projeto de transformaçáo sociocultural. Alguns destaques de sua singularidade encontram-se nas palavras das militantes, a seguir:

- O respeito às diferenças sem perder o rumo na política

“Sim, nos juntamos à 'multidão', mas preservamos nossas lutas." (uma militante).

11 A leitura aqui do movimento feminista brasileiro foi feita por meio de declarações de feministas históricas como de participantes na Articulação das Mulheres Brasileiras, Cfemea, entre outras. 
- O processo político (a luta continuada) para além do evento (manifestaçáo): "continuaremos protestando dentro dos protestos (na esfera pública), dentro das nossas casas (de forma pacífica e discursiva)" (OLIVEIRA; MADSEN, 2013).

- A articulaçáo discursiva entre movimento e atores políticos diversificados:

"[...] encontrar ativistas, debater e buscar nexos entre tantas e diferentes lutas [...] renovação do ativismo feminista, antirracista, contra os fundamentalismos religiosos e anticapitalistas evidentes nas manifestações". (OLIVEIRA; MADSEN, 2013).

- Demandamos modificaçóes na política institucional:

"[...] contra a política de gabinete [...] que exclui os interesses populares e de enfrentamento ao racismo e ao sexismo [...]" (SILVA, 2013, op. cit.).

Nessa direção, pós-manifestaçóes de junho, o movimento feminista que participou da mesma fez suas reflexóes, reafirmando suas lutas tradicionais e renovando sua pauta política à luz dos novos protestos de rua, conforme constam nas falas das manifestantes anteriormente citadas, destacando e reafirmando sua identificação político-cultural com as lutas antirracistas, anticapitalistas e o antifundamentalismo religiosos, entre outros.

\section{Movimentos sociais pró-manifestações ou marchas}

\section{I Marcha Zumbi dos Palmares}

Uma Marcha pré-organizada e que conta com a participaçâo dos movimentos sociais organizados e com continuidade pós-evento poderá ser uma forma de fortalecimento de um tipo de movimento social e de consolidaçáo de suas demandas. Como recentemente afirmou David Harvey: "uma revolução é um processo, não um evento" ${ }^{2}$. Nessa direção, Silva, Trigo e Marçal (2013, p. 566) ajudam a pensar a trajetória emancipatória do movimento negro no Brasil e o respectivo papel da Marcha Zumbi dos Palmares nesse processo, quando afirmam que:

12 Disponivel em: <http://www. hitu.unisinos.br/noticias/527088-vivemos-hoje-no-que-eu-chamaria-de-democraciastotalitarias-entrevista-com-david-harvey>. Acesso em: 18 mar. 2014. 
A "Marcha Zumbi dos Palmares pela vida e contra todas as formas de discriminação", realizada em 20 de novembro de 1995, é considerada um marco para as relações raciais no Brasil. Uma grande mobilização e articulação de centenas de entidades negras levou os ativistas a Brasília.

Pode ser observado, a partir desse importante momento histórico, um redirecionamento do movimento negro em direçáo às lutas por direitos humanos, com especial ênfase à educaçáo, com bem lembram os autores Silva, Trigo e Marçal (2013), as quais se fizeram presentes em processos e conquistas políticas posteriores:

No que diz respeito à educação, o documentol3 traz seis propostas: (1) a exigência de garantia de uma "escola pública, gratuita e de boa qualidade", (2) o monitoramento dos "livros didáticos, manuais escolares e programas educativos", (3) a formação permanente de professores e de educadores para o trato da "diversidade racial", (4) identificação das "práticas discriminatórias", (5) eliminação do analfabetismo e (6) desenvolvimento de "ações afirmativas para o acesso" a curso profissionalizante e à universidade. (SILVA, TRIGO; MARÇAL, 2013, p. 568).

Em 2005, foi realizada a Marcha Zumbi dos Palmares + 10, que também produziu um documento, denominado de "Manifesto à Naçáo", ampliando o escopo das reivindicaçóes, incluindo novos temas em relação à desigualdade racial, sobre questôes de gênero, violência em relação aos negros, entre outras especificidades, e assumiu que "a melhor estratégia para o enfrentamento do racismo e da desigualdade são as 'políticas de ação afirmativa' e as 'políticas de reparaçáo"” (ibid, p. 571), as quais tiveram relevantes avanços institucionais, como a criaçáo da Secretaria Especial de Políticas de Promoçáa de Igualdade Racial, com status de ministério e ligada à Presidência da República; bem como a criaçáo dos Conselhos do Negro e as Conferências Nacional de Promoçáo da Igualdade Racial (três conferências nacionais até o momento), intensificando simultaneamente a luta no campo dos direitos humanos, como a ampla implantação das cotas universitárias, entre outras.

O empoderamento do movimento negro nas últimas décadas possivelmente se relaciona com sua atuação em múltiplas frentes: movimentos organizados, manifestaçóes, conselhos institucionais, fóruns, redes virtuais, entre

13 Documento produzido pela referida marcha e que passou a ser um guia dos movimentos sociais de combate ao racismo e pró ações afirmativas, em especial no campo da educação. 
outras, as quais contribuíram também para avanços na construção de novos saberes emancipatórios, como os relativos às leituras críticas, às formaçóes históricas colonizadas e a sua condiçáo de sujeito na diáspora brasileira ${ }^{14}$.

\section{Manifestações amplas da cidadania e/ou dos “indignados”}

\section{I Manifestações de Junho/2013}

Esse tipo se refere às manifestaçóes de rua contemporâneas, que vêm ocorrendo em diversas esferas públicas mundiais e também no Brasil atual. Sáo convocadas principalmente por múltiplas redes sociais virtuais, que frequentemente existem em torno de algumas afinidades sociais ou políticas, mas que em seu conjunto podem apresentar ideários e ideologias conflitivos, conforme confirmado por confrontos entre manifestantes de rua em $2013 \mathrm{em}$ nosso país.

$\mathrm{Na}$ interpretação de alguns teóricos dos movimentos sociais e do ativismo civil, estes processos mobilizatórios possuem algumas características semelhantes:

Em comum eles têm a identidade como essência organizadora (Castells, 2002), a vontade de transformar valores culturais (Touraine, 2006), o descrédito crescente nas instituições do Estado (Cardoso e Neto, 2003) e a utilização em diferentes níveis das TICs, principalmente das redes da internet, para convocar, organizar, articular, registrar e partilhar informações sobre as causas (Costanza-Chock, 2006). (CARDOSO; DI FÁTIMA, 2013).

Mas perguntamos se em cada manifestaçâo em particular seria possível captar um ou alguns sentidos genéricos de sua realização? O historiador Vianna (2013) busca captar esse sentido político genérico dado pela "multidáo" de junho/2013 no Brasil:

O que querem as multidões de junho de 2013? Antes de tudo, as suas demandas são morais: que o seu voto valha algo, que políticos corruptos sejam presos, que haja desmilitarização das PMs, que não se sintam humilhadas quando precisam recorrer aos serviços públicos e que haja redução nas distorções salariais e legais entre as categorias profissionais. (p. 3).

14 Para uma continuidade dessa análise, vide, entre outros, Reis (2012), Scherer-Warren (2013) e Scherer-Warren e Passos (2014). 
À luz da abordagem do historiador Rudé, Vianna (id.) acrescenta que:

[...] as multidões de junho não são "massas monolíticas manobráveis", mas uma configuração social formada por indivíduos das mais diferentes orientações, expectativas, experiências, faixas etárias, geração e recursos materiais e imateriais [...] (p. 7).

Acrescenta, ainda sobre a mídia, que essa frequentemente interpretou os fatos de forma contraditória, conforme segue:

Nos eventos que observamos em junho, parte da imprensa "livre" está assumindo um papel discursivo de polícia na tipificação das ações dos manifestantes: no começo, a ênfase era no "vandalismo", como se todo o fenômeno se reduzisse a isso; agora, o interesse é domar e moralizar o seu significado, enfatizando que as ações foram ordeiras, pacíficas, apartidárias, com alguns incidentes isolados de "vândalos", que obrigaram a ação da polícia. Raras são as notícias que enfatizam, em tempo de exposição midiática, a presença de partidos políticos categorias sindicais e movimentos sociais [...] (Id., p. 8).

É o papel desses movimentos sociais, antes e pós-manifestaçóes de junho 2013, que busco resgatar nesse momento. Conforme foi observado anteriormente, além das demandas no campo da moral e da política institucional, que existiram, mas foram principalmente referenciadas pela cidadania dos não organizados em movimentos, o que permitiu certo enxameamento civil ${ }^{15}$ na manifestação, é necessário lembrar que as lutas no campo da cultura, dos direitos humanos e por mudanças sistêmicas mais profundas eram as que estavam referenciadas à trajetória histórica e discursiva dos movimentos sociais organizados, os quais buscavam na manifestação pública visibilidade, reconhecimento sociocultural e legitimidade para suas demandas, ainda que nesses casos nem sempre os ganhos políticos sejam visíveis de forma imediata, conforme já mencionado em relação às marchas do movimento negro.

Podemos concluir com Rolnik (2013, p. 9), sobre as manifestaçóes de junho de 2013, que:

A "fagulha" das manifestações de junho não surgiu do nada: foram anos de constituição de uma nova geração de movimentos urbanos - o MPL, a resistência urbana, os movimentos

15 Enxameamento ou swarming civil (MARTINHO, 201I, p. 214) nas "Manifestações de rua são encontros de corpos, mas, antes tudo, na sociedade da informação, funcionam como imagens, produtos simbólicos, signos de mobilização política" e podem funcionar como vetores de agregação, conforme observamos nas manifestações de junho/20/3. 
sem-teto, os movimentos estudantis -, que, entre "catracaços", ocupações e manifestações foram se articulando em redes mais amplas, como os Comitês Populares da Copa e sua articulação nacional, a Ancop.

\section{Manifestações-bloqueio ou "formas de ação nas ruas"}

\section{I Black Blocs (BB)}

Elegemos esse grupo como representante do tipo "manifestação-bloqueio" por ter sido o de maior visibilidade midiática, mas também fruto de interpretaçóes polêmicas e contraditórias. Náo vamos aqui recuperar a história globalizada do fenômeno Black Blocs que em si daria muitos textos e/ou li$\operatorname{vros}^{16}$. No Brasil, os grupos Black Blocs (BB) surgem no início dos anos 2000, influenciados pelas lutas mundiais antiglobalização, com pequenos grupos de ativistas em manifestaçóes-bloqueio de rua em São Paulo e também em Porto Alegre, durante a realização dos Fóruns Sociais Mundiais (FSMs), mas com pouca repercussáo e expressáo política.

Foi somente durante as manifestaçóes de 2013 que os grupos BB vieram a ter mais visibilidade, especialmente devido à divulgação dada pela mídia de massa ${ }^{17}$. Entretanto, essa visibilidade veio acompanhada de leituras opostas sobre seus ideários políticos, que váo do neoanarquismo ao neofascismo ${ }^{18}$. Acreditamos que essa falta de clareza sobre esses grupos prende-se ao fato desse ator supostamente político num contexto de manifestaçóes populares ter se negado a se definir discursivamente numa sociedade da comunicaçáo. Segundo o jornalista historiador Bruno Fiuza"19 "uma das fraquezas dos black blocs hoje (pelo menos em São Paulo): é uma certa fetichização da tática, tomando a formaçáo de blocos negros como um fim em si mesmo". Em

16 Recomendo aqui a leitura do texto de Schlembach (2013) sobre suas origens na Alemanha, nos anos de 1980, e o livro organizado por Ned Ludd (2002) para uma leitura sobre os Black Blocs em sua lutas antiglobalização através do mundo, a partir de 1999.

17 Por exemplo, a Rede Globo preferiu, estrategicamente, centrar-se no pequeno grupo Black Bloc que se manifestava em Brasília, inclusive cancelando parte de sua programação normal para se centrar na transmissão desse grupo. Vide mais detalhes em Scherer-Warren (2014a).

18 Trata-se especialmente de interpretações que circularam nas redes virtuais, mas que merecem estudos $e$ pesquisas atualizados das tendências recentes do fenômeno Black Bloc em escala mundial e, em particular. no Brasil.

19 FIUZA, B. Black Blocs, lições do passado, desafios do futuro. Viomundo. Disponivel em: <blogspot.com. br/2013/I0/black-blocs-origem-da-tatica-que-causa.html>. Acesso em: 17 mar. 2014. 
outras palavras, a expressão estética pode ser impactante como uma forma de linguagem complementar, mas insuficiente se náo for acompanhada por uma melhor explicitação discursiva. Por outro lado, as pesquisas sobre o perfil dos Black Blocs brasileiros ainda não são suficientes, contrastando com um maior conhecimento sobre o assunto no exterior, como, por exemplo, na pesquisa de Francis Dupuis-Déri (2013), que obteve o depoimento de um ativista, o qual caracterizou esse tipo de manifestação como a militância dos desiludidos:

Todos os homens e mulheres que conheço que participaram de black blocs são ativistas, alguns muito experientes. Eles ficaram um tanto desiludidos porque chegaram à conclusão de que os métodos pacíficos são muito limitados e jogam a favor dos poderes no comando. Então, para deixarem de ser vítimas, eles acharam melhor usar a violência. (DUPUIS-DÉRI, $2013)^{20}$.

Numa outra direçáo, Sergio Adorno interpreta a violência na política por parte da sociedade civil como uma ausência de resposta das instituiçóes, ou conforme suas palavras: "a violência ocorre onde há um vácuo na política institucional"21. Todavia permanece ainda a questão: qual seria o perfil político-ideológico predominante dos Black Blocs no Brasil atual? Essa interrogaçáo é um espaço aberto para pesquisas mais aprofundadas.

\section{Ação-manifesto sociocultural}

\section{I Rolezinhos}

Os Rolezinhos sáo agrupamentos especialmente juvenis que se manifestam buscando o reconhecimento cultural, mas se distinguem de outros grupos por focar seus protestos no direito de ir e vir e de ocupar os diferentes territórios sociais, de náo ser discriminados por sua origem social e de usufruir dos mesmos bens de consumo das denominadas elites. Sua presença em massa nos espaços públicos chamados "diferenciados" é que tem gerado o conflito social, típico da açáo dos movimentos sociais, e assim captado a solidariedade de

20 BB2, entrevistado pelo autor. Tradução nossa. A mesma observação foi feita por militantes franceses em Barette, "La Pratique de la Violence Politique par l'Émeute: le Cas de la Violence Exercée lors des Contresommets" (Universidade de Paris I - Panthéon-Sorbonne, 2002), 93. DUPUIS-DÉRI, F. Disponivel em: <http:// www I.folha.uol.com.br/ilustrissima/20 /4/03//422098-um-perfil-historico-dos-black-blocs.shtml>. Acesso em: 17 abr. 2014.

21 Conforme declaração na mesa sobre as Manifestações de rua, no Congresso da SBS, em Salvador, 2013. 
outros movimentos sociais organizados e/ou se constituído num território fértil para a articulaçáo discursiva em torno de outras insurgências, conforme segue:

Esta exaltação do luxo e do consumo, interpretada como adesão ao sistema, tornou o funk da ostentação desconfortável para uma parcela dos intelectuais brasileiros e mesmo para parte das lideranças culturais das periferias de São Paulo. Agora, os rolezinhos - e a repressão que se seguiu a eles - deram a esta vertente do funk uma marca de insurgência, celebrada nos últimos dias por vozes da esquerda. Ao ocupar os shoppings, a juventude pobre e negra das periferias não estava apenas se apropriando dos valores simbólicos, como já fazia pelas letras do funk da ostentação, mas também dos espaços físicos, o que marca uma diferença. E, para alguns setores da sociedade, adiciona um conteúdo perigoso àquele que já foi chamado de "funk do bem". (BRUM, 2014) 22.

Em última análise, os Rolezinhos através de uma prática não convencional de ocupação coletiva de espaços sociais historicamente reservados para as classes sociais mais abastadas, contribuiu para evidenciar e/ou desconstruir a naturalizaçáo dos preconceitos culturais e simbólicos em relaçáo à pobreza, à raça (especialmente a negra) e dos modos de vida das periferias urbanas, entre outros.

\subsection{Lutas de apoio aos Rolezinhos}

Muitos foram os movimentos sociais organizados e também cidadáos em geral que se mobilizaram a favor do manifesto dos Rolezinhos através das redes virtuais ou por outros meios. Selecionamos aqui dois casos simbolicamente relevantes: um do movimento juvenil e outro do denominado movimento popular: duas faces da representação (juvenil e popular).

\section{Levante Popular da Juventude (LPJ):}

O Levante foi criado em 2005 em Porto Alegre, expandindo-se para outros estados, podendo ser hoje caracterizado como um movimento nacional de jovens, com as seguintes características de formaçáo e representaçáo social:

O LPJ nasce da Consulta Popular e da Via Campesina, com ampla penetração na juventude rural. Visava preencher uma lacuna na juventude urbana que carecia de uma organização apartidária e autônoma de jovens. Elegeu 3 campos de atuação: I) no meio estudantil

22 Outros detalhes disponiveis em: <http://www.geledes.org.br/em-debate/colunistas/22863-kaique-e-os-rolezinhoso-lugar-de-cada-um-por-eliane-brum>. Acesso em: 21 fev. 2014. 
secundarista e universitário; 2) nas periferias dos centros urbanos e 3) nos setores camponeses, nesse caso, articulando-se a juventude de outros movimentos sociais, em especial da Via Campesina. ${ }^{23}$

Além disso, abriu seu leque de lutas e reivindicaçóes para contemplar demandas históricas e permitir políticas articulatórias com outros movimentos juvenis, como as contidas nos seguintes relatos do LPJ:

Pauta no campo das políticas públicas para os setores populares: educação, incluindo-se as cotas nas universidades, saúde, transporte, cultura, esporte e lazer. O diferencial do Levante é que não elegemos bandeiras prioritárias, mas nos colocamos ao lado das mobilizações que reivindicam melhores condições de vida para a juventude brasileira. ${ }^{24}$

Nessa mesma direçáo política é que o LPJ, juntamente com outros Movimentos Sociais ou Organizaçóes Populares, apresentou o seguinte Manifesto em relaçáo aos Rolezinhos:

- Anulaçáo imediata das liminares que garantem o direito de segregaçáo aos Shoppings;

- Pedidos públicos de desculpas pela açáo racista por parte dos Shoppings e dos responsáveis pelas liminares no âmbito da Justiça;

- Imediato debate público com governos de todas as esferas sobre a pauta da ampliaçáo dos espaços e condiçóes de acesso a arte, cultura e lazer que possam contribuir para a inclusão, a emancipaçáo e garantia de direitos das juventudes, principalmente da juventude negra, pobre e de periferia.

- Fim do Genocídio da Juventude Negra

- Desmilitarizaçáo das Polícias e amplo debate sobre um novo modelo de segurança Pública para o Brasil. (Disponível em: <http://levante. org.br/cat/noticias/movimento-negro/>. Acesso: 20 fev. 2014).

Portanto, o LPJ constrói desta forma um link de articulaçáo do manifesto sociocultural dos Rolezinhos com as demandas históricas no campo dos

23 Disponivel em: <http://levante.org.br/quem-somos/>. Acesso em: $22 \mathrm{fev} .2014$.

24 Disponivel em: <http://levante.org.br/quem-somos/>. Acesso em: 22 feu. 2014. 
direitos humanos em relação a segregaçóes e discriminaçōes mais amplas, especialmente em relaçáo à juventude no país.

\section{Movimento dos Trabalhadores Sem Teto (MTST)}

O MTST de Sáo Paulo, juntamente com outros movimentos (coletivos Periferia Ativa e Resistência Urbana), organizou uma manifestação de apoio e de solidariedade aos jovens dos Rolezinhos, em 16/01/2014, denominada de Rolezáo Popular, com os objetivos de lutar contra a criminalizaçáo dos movimentos ou manifestos, de defender o direito de ir e vir dos jovens pobres el ou negros das periferias, bem como de outros direitos da cidadania, como ao lazer, à cultura etc. Segundo a coordenadora estadual do MTST, Ana Ribeiro, "a gente está em uma luta por moradia na periferia, mas isso (a luta dos Rolezinhos) é uma luta imediata. Tudo que tem relação com a cidadania do povo da periferia a gente apoia" 25 e, por isso, o apoio aos Rolezinhos.

O que há em comum na ideologia dos dois movimentos de apoio aos Rolezinhos (LPJ e MTST) é a tentativa de dar ênfase à possibilidade de desenvolver uma dimensáo mais politizada aos atos dos Rolezinhos. Buscou-se, assim, no diálogo entre esses dois movimentos construir uma articulaçáo discursiva na defesa do sentido de "popular" e da promoçáo dos respectivos direitos humanos no campo da igualdade, da cultura, do lazer, do respeito à diferença etc.

\subsection{Marcha das Vadias (hibridação entre movimento-manifesto)}

A Marcha das Vadias empiricamente pode ser pensada como um tipo híbrido entre um movimento social já organizado, mas que usa como estratégia principal de luta, as manifestaçóes de rua, com o intuito de transmitir seus protestos e demandas através de referenciais simbólicos para transformaçóes socioculturais $^{26}$. Apesar de a Marcha se considerar como um movimento social, conforme expresso em seu manifesto, ela se distingue dos movimentos sociais organizados em geral e mais tradicionais por rejeitar os mecanismos de institucionalidade em sua estrutura organizacional, preferindo se organizar

25 Disponivel em: <http://www.redebrasilatual.com.br/cidadania/2014/01/movimentos-sociais-fazem-rolezaocontra-discriminacao-em-sao-paulo-1272.htm>. Acesso em: mar. 2014.

26 Sua primeira manifestação foi realizada no Canadá em 2011 , e no Brasil em 2012. 
como uma rede interpessoal de militantes ${ }^{27}$ e por colocar na visibilidade pública sua principal estratégia. Portanto, esta Marcha situa-se na encruzilhada de um movimento que se organiza para sua continuidade histórica e uma forma estética de manifestaçáo pública. Portanto, a Marcha das Vadias pode ser um exemplo de ação-manifesto, centrada na luta por mudanças socioculturais com respeito à diversidade e à igualdade de direitos e, como tática, faz o uso político de estéticas e simbologias contestatórias e abertas à articulação das diferenças na política, conforme se expressou através de seu Manifesto: "Vadia por quê?".

A Marcha das Vadias do Rio de Janeiro se reconhece como um movimento social não institucional, apartidário formado por pessoas que se identificam com a defesa da autonomia dos corpos, com a defesa dos direitos sexuais e reprodutivos e com a luta por justiça social. A Marcha é apartidária e, mais uma vez, em 2013 convidamos partidos, sindicatos, coletivos e organizações que queiram trazer suas pautas e construir seus cartazes, pinturas e demais intervenções "artivistas" junto conosco [...] Afirmamos a igualdade de direitos e não discriminação a mulheres, lésbicas, gays, pessoas bissexuais, travestis, transexuais, profissionais do sexo, prostitutas, de todas as cores, formatos e classes sociais [...] (Marcha de 27/7/2013, Rio). (Disponível em: <http://marchadasvadiasrio.blogspot.com.br/ search?updated-min=20 I3-0 I-0 I T00:00:00-08:00Eupdated-max=20 I 4-0 I-0 I T00:00:0008:00Emax-results $=9>$ ).

Enfim, enquanto expressão da hibridação entre movimento social organizado e açáo-manifesto sociocultural, a Marcha das Vadias se caracteriza por ser uma articulaçáo de um coletivo de ativistas, que se comunicam, sobretudo, através das redes sociais virtuais e por sua aposta em protestos públicos nas ruas e na internet, utilizando-se de expressóes simbólicas, linguísticas e de imagens impactantes, como, por exemplo: a exposiçáo do corpo nu nas manifestaçóes de rua e na internet, enquanto ato de politizaçáo com o objetivo de desconstruir a naturalizaçáo do machismo e de suas expressóes simbólicas. ${ }^{28}$

27 Por exemplo, "A marcha das Vadias de Florianópolis, assim se define: 'Esclarecemos, conforme decidido nas reuniōes, que a Marcha das Vadias de Florianópolis possui caráter anti-institucional, não sendo vinculada a qualquer bandeira, grupo ou partido político. Não queremos ser aparelhadas enquanto marketing de empresas, ONGs, partidos ou qualquer tipo de instituição. Deixando claro que estamos abertas ao diálogo e construção coletiva e horizontal. Queremos uma Marcha construida por pessoas para pessoas!'” (Disponivel em: <http://www.midiaindependente.org/pt/green/20/3/04/5/8746.shtml>. Acesso em: I4 jan. 20/4).

28 Vide mais detalhamentos em: FERREIRA, G. Feminismo e redes sociais na Marcha das Vadias no Brasil. Revista Ártemis, v. XV, n. I, p. 33-43, jan./jul. 2013. 


\section{Considerações finais}

Concluímos que a relaçáo entre movimentos sociais organizados, o ativismo cidadáo de uma forma mais ampla e a atuação nas manifestaçóes públicas, vem indicando avanços no campo político da cidadania para além daquelas referentes às demandas no campo das políticas institucionais e governamentais, essas últimas predominantes nas interpretaçóes das mídias de massa. Destacam-se as lutas, os projetos e as utopias nas seguintes direçóes: mudanças sistêmicas; mudanças sociopoliticas e culturais; demandas no campo dos direitos humanos e politicas de empoderamento da cidadania, as quais, a partir da leitura sobre a participaçáo dos grupos contemplados neste estudo, podem ser sintetizadas em torno de uma relativa e sempre provisória centralidade, apoiadas em referências empíricas, que contemplam as seguintes tendências movimentalistas emancipatórias aqui contempladas:

- A organizaçáo e a reestruturaçáo urbana e o direito à cidade para todos (Movimento Passe Livre - MPL, Movimento dos Trabalhadores Sem Teto - MTST); e o combate à globalização neoliberal (Black Bloc- BB);

- A superaçáo de desigualdades sociais e direito às diferenças socioculturais (movimentos feministas, etnorraciais, Marcha das Vadias);

- O empoderamento e a articulaçáo política do movimento popular (Levante Popular da Juventude - LPJ e Movimento dos Trabalhadores Sem Teto - MTST);

- O reconhecimento e a inclusão sociocultural (movimentos feministas, movimentos negros, Rolezinhos);

- As políticas de reparaçáo racial-étnicas e as açóes afirmativas (movimentos negros e Marcha Zumbi dos Palmares - MZP).

Resta lembrar que a articulaçáo discursiva construída na prática política desses movimentos sociais organizados e em suas relaçóes com as manifestaçóes de rua vem permitindo uma identificação na política mais abrangente que as especificidades de cada movimento, bem como a construçáo de novos significados simbólicos compartilhados, empoderando, assim, a cidadania politicamente ativa. 


\section{Referências}

CARDOSO, G.; DI FÁTIMA, B. Movimento em rede e protestos no Brasil: Qual gigante acordou? Dossiê Mídia, Intelectuais e Política - www.pos.eco.ufrj.br, v. 16, n. 2, p. 143-176, maio/ ago. 2013.

CARDOSO, G.; PEREIRA NETO, P. REBELO, J. (Coord.). O movimento por Timor: mass media e protestos online. In: NOVAS formas de mobilização popular. Lisboa: Campo das Letras, 2003. p. 105-121.

CASSOLI, A. Movimento passe-livre de Florianópolis e o enfrentamento do Estado neo-liberal: algumas consideraçóes. 2010. [Artigo de conclusáo da disciplina Tópicos especiais: movimentos sociais: para uma abordagem pós-colonial, do PPGSP/UFSC]. Disponível em: <http://www. academia.edu/>.

CASTELLS, M. A sociedade em rede: a era da informação: economia, sociedade e cultura, Lisboa: Fundação Calouste Gulbenkian, 2002.

COSTANZA-CHOCK, S. Analytical note: horizontal communication and social movements. In: MASSACHUSETTS INSTITUTE OF TECHNOLOGY, [online], 2006. Disponível em: <http://web.mit.edu/schock/www/docs/horizonal\%20communication\%20and\%20social\%20 movements.pdf>. Acesso em: fev. 2014.

FERREIRA, G. Feminismo e redes sociais na Marcha das Vadias no Brasil. Revista Ártemis, v. XV, n. 1, jan./jul. 2013.

GUERRA, A. Nós, manifestantes feministas. Jornal Fêmea, Cfemea, Brasília (DF), n. 175, p. 3, nov./dez. 2013.

HARDT, M.; NEGRI, A. Multidáo. Rio de Janeiro: Record, 2005.

LACLAU, E. Emancipaçáo e diferença. Rio de Janeiro: Ed. UERJ, 2011.

LUDD, N. (Org.). Urgência das ruas: Black Block, Reclaim the Streets e os Dias de Ação Global. São Paulo: Conrad, 2002.

MARON, W. M. Resenha de "la razón populista": Ernesto Laclau. Revista Digital AdVerbum, v. 7, n. 1, p. 60-62, jan./jul. 2012.

MARTINHO, C. Dinâmicas de propagação e swarming. In: MARTINHO, C.; FELIX, C. (Org.). Vida em redes: relacionamento e caminhos para uma nova sociedade. Barueri: Instituto C\&A, 2011.

MOUfFE, C. Democracia, cidadania e a questáo do pluralismo. Política \& Sociedade, 2003. v.2, n.3, p. 11-26, out.2003. Disponível em: <https://periodicos.ufsc.br/index.php/politica/article/ view/2015>] 
OLIVEIRA, G. de; MADSEN, N. As jornadas de junho e o novo cenário político brasileiro. Jornal Fêmea, Cfemea, Brasília (DF), n. 175, nov./dez. 2013.

REIS, M. L. M. dos. Diáspora como movimento social: políticas de combate do racismo em perspectiva transnacional. 2012. Tese (Doutorado em Sociologia Política) - Universidade Federal de Santa Catarina, Florianópolis, 2012.

ROLNIK, R. Apresentaçáo: as vozes das ruas: as revoltas de junho e suas interpretaçóes. In: MARICATO, E. et al. Cidades rebeldes: passe livre e as manifestaçóes que tomaram as ruas do Brasil. São Paulo: Boitempo: Carta Maior, 2013.

RUDÉ, G. A multidáo na história, 1730- 1848. Rio de Janeiro: Campus, 1991.

SARAIVA, A. Movimentos em movimento: uma visáo comparativa de dois movimentos sociais juvenis no Brasil e Estados Unidos. 2010. Tese (Doutorado) - Instituto de Ciências Sociais, Centro de Pesquisa e Pós-Graduaçáo sobre as Américas da Universidade de Brasília, Universidade de Brasília, 2010.

SCHERER-WARREN, I. Redes e movimentos sociais projetando o futuro. Revista Brasileira de Sociologia, v. 1, n. 1, jan./jul. 2013. Disponível em: < http://www.sbsociologia.com.br/revista/ index.php/RBS/article/view/29/9>. Acesso em: mar. 2014.

Manifestaçóes de rua no Brasil 2013: encontros e desencontros na política: Salvador. Cadernos CRH, [online], v. 27, n. 71, p. 417-429, 2014a. Disponível em: <http://dx.doi. org/10.1590/S0103-49792014000200012>.

Redes de movimentos sociais. 6. ed. Sáo Paulo: Loyola, 2014b.

Redes emancipatórias: nas lutas contra a exclusão e por direitos humanos. Curitiba: Appris, 2012a.

Redes e incidências nas políticas públicas: entre as singularidades e as universalidades. In: MARTINS, P. H.; RODRIGUES, C. (Org.). Fronteiras abertas da América Latina. Recife: Ed. Universitária da UFPE, 2012b.

Redes da sociedade civil: advocacy e incidências possíveis. In: MARTINHO, C.; FELIX, C. (Org.). Vida em redes: relacionamento e caminhos para uma nova sociedade. Barueri: Instituto C\&A, 2011.

SCHERER-WARREN, I.; PASSOS, J. C. dos (Org.). Relaçôes étnico-raciais nas universalidades: os controversos caminhos da inclusão. Florianópolis: Atilènde, 2014.

SCHLEMBACH, R. "Autonomous Nationalists": new developments and contradictions in the German neo-Nazi movement. Interface: a journal for and about social movements, v. 5, n. 2, p. 295-318, nov. 2013. 
SILVA, C. Multidōes nas ruas mudam a conjuntura do país. Jornal Fêmea, Cfemea, Brasília (DF), n. 175 , nov./dez. 2013.

SILVA, P. V. B. da; TRIGO, R. A. E.; MARÇAL, J. A. Movimentos negros e direitos humanos. Rev. Diálogo Educ., Curitiba, v. 13, n. 39, p. 559-581, maio/ago. 2013. Disponível em: <http://www. redalyc.org/articulo.oa?id=189128924007>.

TOURAINE, A. Na fronteira dos movimentos sociais. Revista Sociedade e Estado, [online], v. 21, n. 1, Brasília (DF), Departamento de Sociologia da Universidade de Brasília (UnB), 2006. Disponível em: <www.scielo.br/pdf/se/v21n1/v21n1a03.pdf>.

VIANNA, A. M. As multidóes de junho de 2013 no Brasil: o desafio de explicar e compreender. Revista Espaço Acadêmico, n. 146, jul. 2013.

\section{From social movements to street manifestations: Brazilian activism in the 2 I st century}

\section{Abstract}

How should we distinguish between the several types of activism in contemporary Brazil, taking into account the types of organization, public policies, sociocultural and political ideals, propositions and claims? Considering this aim, I will begin my article by proposing a typology to distinguish historical social movements from cyclical street manifestations, and, following this, verify how and when the organized social movements express themselves politically through street manifestations and how such manifestations exceed the political discourse established by social movements. Next, I shall examine whether organized social movements have been impacted by street manifestations and whether they have incorporated or consolidated transversal demands in their political agendas.

Keywords: Social movements. Social activism. Streets manifestations. 